\title{
TEORIA PICTÓRICA NO TRACTATUS DE WITTGENSTEIN
}

\author{
$\underline{\text { Juan Erlle Cunha de Oliveira }}{ }^{1}$; Wagner Teles de Oliveira ${ }^{2}$ \\ 1. Bolsista FAPEBS/PIBIC, Graduando em Filosofia, Universidade Estadual de Feira de Santana, e-mail: \\ juan.erlle@gmail.com \\ 2. Orientador, Departamento de Ciências Humanas e Filosofia, Universidade Estadual de Feira de Santana, e-mail: \\ woteles@gmail.com
}

PALAVRAS-CHAVE: Proposição; teoria pictórica; linguagem.

\section{INTRODUÇÃO}

A linguagem em Wittgenstein pode ser entendida, em certo sentido, como uma instância que refrata a realidade do mundo, mais especificamente da ligação lógica entre os objetos, os estados de coisas (2.01). Mesmo como domínio linguístico distinto, a rigor, do real, a sua capacidade figurativa pressupõe uma identidade formal com o afigurado. É só através dessa relação interna que é dada à linguagem a virtude de dizer o que pode ser dito. Muito além de apontar essa ligação entre mundo e linguagem, é preciso agora mostrar como, efetivamente, essa correlação se dá. Neste sentido, o objetivo desse trabalho é analisar os principais conceitos da Teoria Pictórica no Tractatus Logico-Philosophicus para entender como se estabelece a ligação interna entre mundo e linguagem, condição indispensável para a figuração.

\section{MATERIAL E MÉTODOS OU METODOLOGIA (ou equivalente)}

O Tractatus tem uma forma de argumentação bastante peculiar, sendo dividido por proposições numeradas de acordo com o seu peso lógico. As proposições mais destacadas são indicadas por decimais, cuja explicação é fixada nas proposições subsequentes .Observações relativas à proposição $n$ formam proposições do tipo $n .1$, que podem ensejar uma proposição n.m.1 e assim sucessivamente. A definição de qualquer conceito segue, portanto, essa ordem lógica, ao ponto de remontar-se à obra em sua unidade. O estudo foi feito a partir de uma leitura exclusivamente internalista do Tractatus e na sequência que o livro se dispõe, não se furtando, contudo, do confronto com comentadores que possivelmente ajudaram a fixar interpretações da obra.

WITTGENSTEIN, Ludwig. Tractatus LogicoPhilosophicus. 3.ed. 2.reimp. São Paulo: EDUSP, 2010.

A primeira tradução do Tractatus Logico-Philosophicus no Brasil foi feita em 1968, aos cuidados de José Arthur Giannotti. Levando em conta que a sua tradução se ressente da pouca quantidade de material crítico sobre Wittgenstein disponível à época, Giannotti planeja retraduzir a obra, mas acaba por transferir essa tarefa a Luiz Henrique Lopes dos Santos. A matriz para essa nova tradução, publicada pela primeira vez em 1993, é a edição bilíngue alemão-inglês de 1961, traduzida por David Pears e B. McGuiness. Contudo, Luiz Henrique consulta a correspondência Wittgenstein-C. K. Ogden, subsequente à publicação de 1921, de modo a levar em conta diversas sugestões de aperfeiçoamento da tradução em inglês que o autor do Tratactus ali expõe aos seus primeiros tradutores - C.K. Ogden e P. F. Ramsey. A qualidade da tradução utilizada por nós se fundamenta na minuciosa consulta das fontes primárias essenciais empreendidas pelo estudioso e tradutor. O estudo crítico que precede a tradução da obra se tornou um clássico da bibliografia secundária em português, razão pela qual é um segundo testemunho da qualidade da fonte primária por nós eleita. 


\section{RESULTADOS E/OU DISCUSSÃO (ou Análise e discussão dos resultados)}

Toda figuração, qualquer que seja ela, não se constitui como uma mistura de sinais linguísticos, mas é articulada ao se relacionar internamente com o afigurado através da forma de afiguração. ${ }^{1}$ Se se trata de uma figuração espacial, uma maquete, por exemplo, a sua forma é o espacial. O mesmo ocorre com uma partitura de música. Assim, se os objetos figurados se enlaçam conforme a sua forma lógica e por forma de afiguração se entende como "possibilidade de que as coisas estejam umas para as outras tal como os elementos da figuração", então a forma de afiguração é forma lógica de afiguração. Em outras palavras, a forma de afiguração, no plano ontológico, é a própria forma lógica dos objetos, cujo modo de articulação, para que a figuração seja instituída, deve ser sintaticamente correlacionada nos elementos da figuração, articulando-se.

O aforismo 4.014 apresenta figurações musicais diferentes, mas cujo traço em comum é uma mesma forma de afiguração. O embaraço, entretanto, surge quando notamos que cada figuração se constitui, em sua superfície, de elementos distintos: os sulcos no disco, a música como uma ideia, a partitura que inscreve notas musicais num plano bidimensional. É trivial exigir que, numa simulação com miniaturas, o automóvel A e B estejam na mesma distância mantida entre os carros no caso real. Ora, situações não podem ser nomeadas, ${ }^{3}$ tampouco podemos aventar que os elementos de uma figuração, depois de fazer figuração, sejam exclusivos daquele afigurado. As miniaturas de automóveis, por exemplo, podem estar na mesma posição e distância e ainda assim figurar fatos distintos, mas com mesma forma de afiguração. Que uma partitura se constitui como uma figuração musical é algo tão trivializado que não prescindimos de uma análise lógica. Em contrapartida, o que garante que dois objetos "desconhecidos" postos em uma mesa representam dois carros momentos antes de um acidente e não um simples fluxo de trânsito? Como entendemos, portanto, uma proposição sem que ela nos tenha sido explicada? Esse problema, que a Teoria Pictórica dissolve, envolve o estatuto da nomeação, como as regras que determinam a vinculação do nome ao significado. Um símbolo, que é o caso do nome, pode ser representado sensivelmente por dois sinais $^{4}$ e as figurações permanecerem essencialmente idênticas. É o caso dos exemplos acima. Mas parece que estamos andando em círculo quando nos deparamos com a afirmação de que "é só no contexto da proposição que um nome tem significado". 5

É aqui que a chamada lei de projeção faz água. A proposição se estabelece em sua relação projetiva com o mundo; ela vai até a realidade ${ }^{6} \mathrm{e}$, como régua aposta à realidade, "apenas os pontos mais externos das marcas da régua tocam o objeto a ser medido". 7 À projeção sobrevém a relação afiguradora com o mundo, a partir da qual os elementos da proposição, as palavras, se coordenam, ponto a ponto, tal como os objetos do afigurado. Assim, o sinal proposicional se converte em símbolo proposicional e o objeto passa a ter, na proposição, o nome que tem. O que a projeção projeta, portanto, é o sentido, uma situação possível, mas "a figuração representa o que represente, independentemente de sua verdade" . É neste sentido que, no tocante aos diferentes modos de fazer afiguração musical, a projeção elucida que a diferença é de superfície e entre os sinais. No que importa à sintaxe lógica, os nomes têm os mesmos significados e as figurações têm o mesmo fato. .

\footnotetext{
${ }^{1}$ WITTGENSTEIN, Ludwig. Tractatus Logico-Philosophicus, 2.17.

${ }^{2}$ WITTGENSTEIN, Ludwig. Tractatus Logico-Philosophicus, 2.151.

${ }^{3}$ WITTGENSTEIN, Ludwig. Tractatus Logico-Philosophicus, 3.144.

${ }^{4}$ WITTGENSTEIN, Ludwig. Tractatus Logico-Philosophicus, 3321.

${ }^{5}$ WITTGENSTEIN, Ludwig. Tractatus Logico-Philosophicus, 3.3.

${ }^{6}$ WITTGENSTEIN, Ludwig. Tractatus Logico-Philosophicus, 2.1511.

${ }^{7}$ WITTGENSTEIN, Ludwig. Tractatus Logico-Philosophicus, 2.15121.

${ }^{8}$ WITTGENSTEIN, Ludwig. Tractatus Logico-Philosophicus, 2.22.
} 
Figurar um fato significa projetar uma ordem de coisas na linguagem, a partir da qual os elementos simples são configurados de uma determinada maneira porque estão em relação projetiva com os seus significados. Na medida em que o nome não está inscrito na natureza do objeto, é só dentro de uma proposição já instituída que o nome ganha significado que tem. O nome representa, na figuração, o objeto, o qual é tocado na relação afigurante. Assim, entender o sentido de uma proposição significa, portanto, saber qual objeto o nome representa. E já que figuração e afigurado compartilham a mesma forma lógica, o nome também possui todas as suas possibilidades de ligação com outros nomes, ao que Margutti Pinto chama de forma do nome. ${ }^{9}$

Wittgenstein parece se inspirar num kantismo mais mitigado aos deslocar as condições a priori da apercepção do sujeito transcendental para a ideia de forma lógica como nova condição a priori da constituição do mundo. O sujeito kantiano é então substituído pelo simbolismo, "que torna possível pensar algo enquanto objeto, sem que seja preciso recorrer às supostas formas a priori da percepção". ${ }^{10}$

\section{CONSIDERAÇÕES FINAIS (ou Conclusão)}

A Teoria Pictórica, no Tractatus, mostra como se estabelece a ligação interna entre mundo e linguagem e a condição lógica de todo discurso, não importa qual seja o seu valor de verdade. A forma de afiguração determina de que modo a figuração se estrutura, obedecendo as configurações dos objetos do afigurado, mas é na projeção que os elementos ganham significado.

Não obstante, as relações afigurantes não podem ser figuradas, mas mostradas. É por isso que, de sua marca transcendental, a lógica da linguagem não se situa no mundo, mas fora dele, isto é, fora do universo do dizível. A pertinência desse tema, que nos leva ao conceito de nomeação, não se esgota no Tractatus. Trata-se de uma questão que tem desdobramentos importantes para a compreensão do sentido da obra futura de Wittgenstein, como as Investigações Filosóficas.

\section{REFERÊNCIAS}

CUTER, J. G. Por que o Tractatus necessita de um sujeito transcendental? In: Dois Pontos. Curitiba, São Carlos, vol. 3, n. 1, p.171-192, abril, 2006.

CUTER, J. G. Subjetividade empírica e transcendental no Tractatus de Wittgenstein. In: PHILÓSOPHOS. Goiânia, 8 (1) : 79-86, jan./jun. 2003.

GLOCK, Hans-Johann. Dicionário Wittgenstein. Rio de Janeiro: Jorge Zahar, 1998.

GRIFFIN, JAMES. O Atomismo Lógico de Wittgenstein. Trad. Marina Ramos Themudo e Vítor Moura. Portugal: Porto Editora, 1998.

HACKER, P.M.S. Insight and Illusion: Wittgenstein on Philosophy and the Metaphysics of Experience. Oxford: Clarendon Press, 1972.

HINTIKKA, J. Uma investigação sobre Wittgenstein. Campinas: Papirus, 1994.

MARQUES, Edgard D. da Rocha. Sobrea Distinção entre Tatsche e Sachverhalt no Tractatus Logico-Philosophicus de Ludwig Wittgenstein.

MONK, Ray. Wittgenstein: o dever do gênio. Trad. Carlos Afonso Malferrari. São Paulo: Companhia das Letras, 1995.

\footnotetext{
${ }^{9}$ MARGUTTI PINTO, Paulo Roberto Margutti. Iniciação ao silêncio, p. 197.

${ }^{10}$ MORENO, Arley. Introdução a uma pragmática filosófica, p. 19.
} 
MORENO, Arley R. Wittgenstein: os labirintos da linguagem: ensaio introdutório. São Paulo: Moderna, 2000.

PEARS, David. As idéias de Wittgenstein. Tradução de Octanny Silveira da Mota e Leônidas Hegenberg. São Paulo: Cultrix, 1971.

PINTO, Paulo Roberto Margutti. Iniciação ao silêncio: análise do Tractatus de Wittgenstein. São Paulo: edições Loyola (coleção Filosofia), 1998.

SALLES, João Carlos. “Algumas Considerações sobre Deus e Suas Circunstâncias”. In: O Retrato do Vermelho e Outros Ensaios. Salvador: Quarteto, 2016. p. 105-120.

SANTOS, Luiz Henrique Lopes dos. “A Essência da Proposição e a Essência do Mundo”. In: Tractatus Logico-Philosophicus, Edusp, São Paulo, 2008.

WITTGENSTEIN, Ludwig. Tractatus LogicoPhilosophicus. 3.ed. 2.reimp. São Paulo. 